\title{
Effect of platelet rich fibrin and beta tricalcium phosphate on bone healing. A histological study in pigs ${ }^{1}$
}

\author{
Dincer Yilmaz ${ }^{\mathrm{I}}$, Necdet Dogan", Aydin Ozkan ${ }^{\mathrm{III}}$, Metin Sencimen ${ }^{\mathrm{IV}}$, Baris Eren Ora ${ }^{\mathrm{IV}}$, Ibrahim Mutlu ${ }^{\mathrm{VI}}$ \\ ${ }^{\mathrm{I}} \mathrm{PhD}$, Oral and Maxillofacial Surgeon, Ardahan Military Hospital, Dental Service, Ardahan, Turkey. Design of the study, surgical procedures. \\ IIPhD, Professor, Department of Oral and Maxillofacial Surgery, Dental Sciences Center, Gulhane Military Medical Academy, Ankara, Turkey. \\ Designed the protocol, intellectual and scientific content of the study. \\ IIIDDS, PhD, Oral and Maxillofacial Surgeon, Head of Surgical Infirmary, Land Forces Practice Center, Ankara, Turkey. Design and scientific content \\ of the study, English language, manuscript writing.

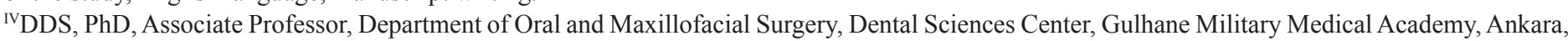 \\ Turkey. Histological procedures, critical revision. \\ ${ }^{\vee}$ DDS, PhD, Oral and Maxillofacial Surgeon, Etimesgut Military Hospital, Dental Service, Ankara, Turkey. Surgical and histological procedures, \\ manuscript writing. \\ ${ }^{\mathrm{VI} D D S}$, PhD, Oral and Maxillofacial Surgeon, Tatvan Military Hospital, Dental Service, Bitlis, Turkey. Acquisition of data, statistical analysis.
}

\begin{abstract}
PURPOSE: To investigate the effect of platelet rich fibrin (PRF) and beta tricalcium phosphate ( $\beta$-TCP), alone or in combination, on bone regeneration in pig tibial defects.

METHODS: Four standardized defects were prepared in both tibias of three adult male pigs. The first defect was left unfilled as a control; the others were grafted with either PRF, $\beta$-TCP or PRF mixed with $\beta$-TCP. All animals were sacrificed on the $12^{\text {th }}$ postoperative week and the tibial bones were removed, histologic sections were prepared and the experimental sites were examined microscopically and stereologically.
\end{abstract}

RESULTS: Histologic and stereologic examination revealed more new bone formation in the defects filled with PRF mixed $\beta$-TCP than in the defects grafted with either $\beta$-TCP or PRF alone.

CONCLUSION: The platelet rich fibrin and beta tricalcium phosphate combination effectively induces new bone formation.

Key words: Calcium Phosphates. Bone Regeneration. Tibia, Blood Platelets. Swine. 


\section{Introduction}

An autogenous bone graft is considered the gold standard in maxillofacial surgery because of its osteoinductive and osteoconductive features and the fact that it does not cause immunological problems. However, the use of such grafts is limited because they involve a second operative site and have an uncontrolled resorption period ${ }^{1,2}$ As a result, non-toxic and non-immunologic alloplastic materials have been used in order to diminish these disadvantages ${ }^{3}$. Among these materials, the most prevalent is beta tricalcium phosphate $(\beta$-TCP). $\beta$-TCP has the properties of high biocompatibility and osteoconductivity $^{4,5}$. Because of these features, $\beta$-TCP leads to bone apposition in the areas contacting with the material ${ }^{6}$.

Nowadays, a number of different growth factors are used together with graft materials or by themself in maxillofacial surgery. Among these is platelet-rich fibrin (PRF). PRF was developed by Dohan et al. ${ }^{7}$. With this simplified technique, an autologous fibrin matrix, which contains platelets and leucocyte growth factors, is obtained.

The aim of this study was to compare histologically and stereologically the healing effects of $\beta$-TCP or PRF alone or in combination in standardized bony defects in the pig tibia.

\section{Methods}

The study protocol was reviewed and approved by the Animal Care Committee at the Gulhane Military Medical Academy under protocol number 08/61 (Ankara, Turkey). Three male pigs with an average weight of $60 \pm 5 \mathrm{~kg}$ and aged 8 -months were used in the study.

Four bone defects $5 \mathrm{~mm}$ in diameter and $5 \mathrm{~mm}$ deep, placed at $10 \mathrm{~mm}$ intervals, were prepared in each tibia of the experimental animals for a total of 24 defects. These were divided into four groups according to the type of material used. In first group; the defects remained unfilled and served as a control. In the second group; the defects were filled with PRF and in the third group; they were filled with $\beta$-TCP. In the fourth group the defects were filled with 50\% $\beta$-TCP and $50 \%$ PRF.

\section{PRF preparation}

PRF was prepared using the technique described by Dohan et al. ${ }^{7}$. Immediately after $10 \mathrm{cc}$ of blood had been drawn from the ear vein of each pig, the sample was centrifuged in a $10-\mathrm{mL}$ sterile tube (without anticoagulant) at $400 \mathrm{~g}$ for $10 \mathrm{~min}$ using a laboratory centrifuge (NF 800, Nuve, Ankara, Turkey). Using forceps, the PRF gel was removed from the middle layer of the sample, which was located between the red corpuscles at the bottom of the tube and the acellular plasma at the top of the tube.

\section{$\beta-$ TCP granules}

In this study, Kasios (Kasios ${ }^{\circledR} \mathrm{TCF}$, Launaguet, France), containing 1000-2000 $\mu \mathrm{m} \beta$-TCP(Ca3(PO4)2) particles of synthetic phosphocalcium ceramics was used as the graft material. When used alone, $2 \mathrm{~g}$ of the $\beta$-TCP granules were tightly packed into the defect.

\section{Surgical protocol}

The surgery was performed under general anesthesia with intubation using a sterile technique. In addition $1.0 \mathrm{~mL}$ of a local anesthetic ( $2 \%$ lidocaine with adrenaline, 1:80 000) was injected in the surgical site. A longitudinal skin incision was made on the medial side of the tibia and the periosteum was incised and reflected to expose the bone surface. The $5 \mathrm{~mm}$ deep cavities were then prepared under saline irrigation with a trephine drill. After placing all the graft materials (Figure 1), the wound was closed with resorbable sutures (Vicryl 3.0; Ethicon, Norderstedt, Germany). To prevent infection, the pigs were given Pan-Terramycin (Pfizer, New York, USA) at $7.5 \mathrm{mg}$ / $\mathrm{kg}$ daily during the first three postoperative days. 

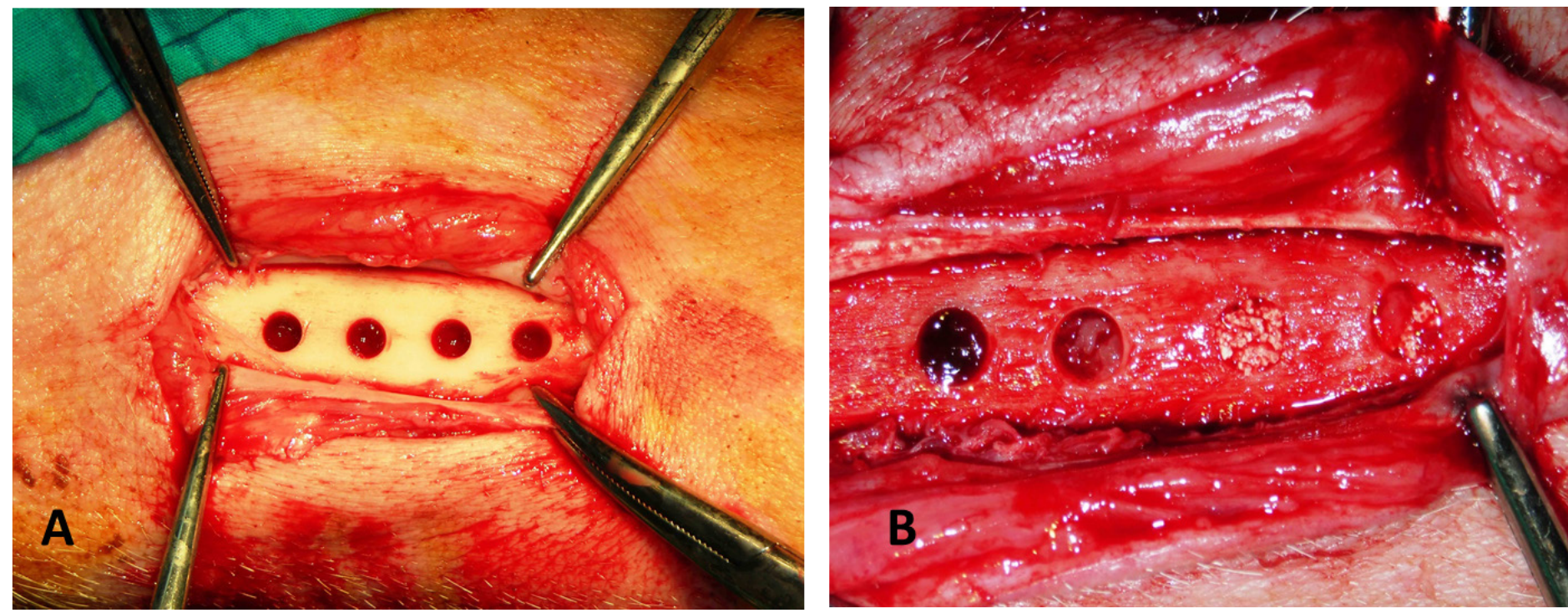

FIGURE 1 - Intraoperative photograph of the experiment. (A) Four $5 \mathrm{~mm}$ diameter defects were made in pig tibia. (B) PRF, $\beta$-TCP PRF/ $\beta$-TCP graft materials in the defects.

The pigs were sacrificed using an IV injection of ketamine $\mathrm{HCl}(>150 \mathrm{mg} / \mathrm{kg})$ at 12 weeks postoperatively. The tibias were removed and fixed in $10 \%$ formalin solution.

\section{Preparation of the specimens}

After fixation, four holes makers were made with a small round bur and computerized tomography was done to identify the exact location of the individual defects. The defect areas were marked and separated in such a way that 2-3 mm of bone was left on both the proximal and distal sides of each defect. All specimens were then immediately dehydrated with a graded series of alcohols. Following dehydration, the specimens were infiltrated with a lightcuring embedding resin (Technovit 7200 VLC, Heraeus Kulzer, Wehrheim, Germany). Following infiltration with constant shaking at normal atmospheric pressure, the specimens were embedded and polymerized by $450-\mathrm{nm}$ light. The temperature of the specimens never exceeded $40^{\circ} \mathrm{C}$. The specimens were then prepared by the cutting-grinding method of Donath and Breuner ${ }^{8}$. The specimens were cut to a thickness of $150 \mu \mathrm{m}$ on an EXAKT cutting-grinding system (EXAKT Apparatebau, Norderstedt, Germany). Following this, the specimens were polished to a thickness of $40 \mu \mathrm{m}$ using the EXAKT microgrinding system, followed by alumina polishing paste. Then, the specimens were stained with toluidine blue solution. After staining, all specimens were glued with Technovit 7210 adhesive (Heraeus Kulzer, Wehrheim, Germany) to prepared glass slides.

\section{Histology and stereology}

The histologic examination was done with a light microscope (Nicon, Tokyo, Japan) using x2.5, x4 and x10 magnifications. Also, sections were used for the stereologic analysis. Stereologic analyses were conducted by viewing the sections on a Leica DM4000B microscope (Leica, Wetzlar, Germany) which had been fitted with an integrated, computerguided microscopy system and Stereo Investigator software (ver. 5.05, MicroBrightfield, Williston VT, USA). In each section the area, including the adjacent empty spaces was traced under a x2.5 magnification and 17 to 30 random microphotographs were obtained. Then all of the microphotographs were united creating just a single photo and enlarged to final magnification of $x 150$. The photos were transferred to a personal computer via MBF Stereo Investigator software. "Point Counting Method" (Cavalieri) used for measuring the area. Calibration was set as $500 \times 500=250.000$ $\mu \mathrm{m}^{2}$ for each unit. At the end of examination the new bone tissue area was calculated for each slide.

\section{Statistical analysis}

Statistical analyses were performed using the SPSS software package (Statistical Package for Social sciences for Windows, version 13.0, SPSS Inc., Chicago, USA). KruskalWallis was used to compare means of continuous variables for the different groups. The groups in which a statistically difference was observed were compared in multiple pairs by the Mann-Whitney-U test with Bonferroni correction significance set at $\mathrm{p}<0.05$. 


\section{Results}

\section{Histologic findings}

\section{Group 1 (Control Group)}

Most of the defect area was filled with immature bone. There were only a small number of osteocytes and osteons and Volkmann canals were lacking (Figure 2).

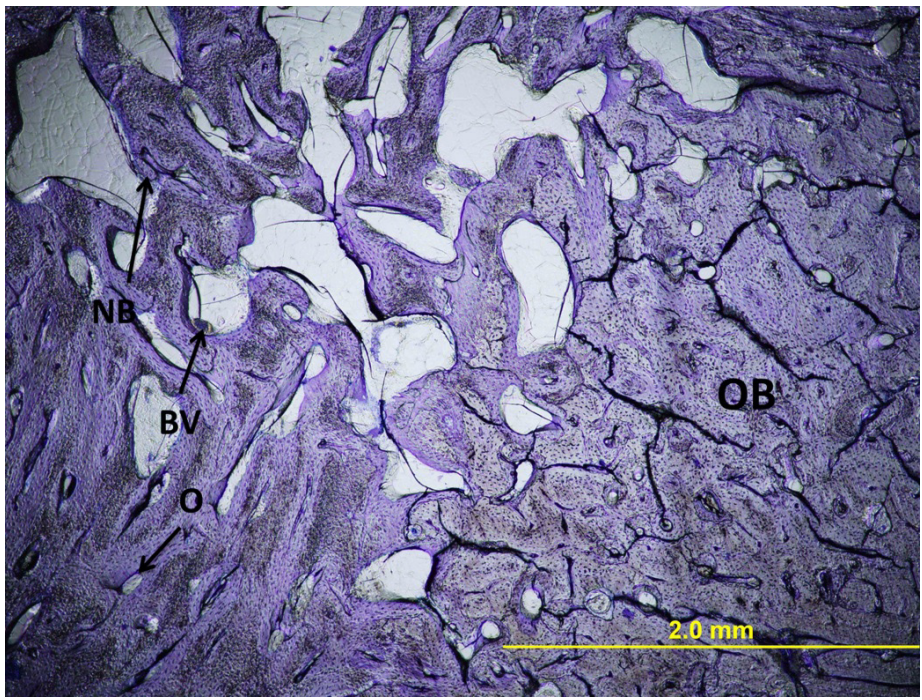

FIGURE 2 - Light micrograph of histology of an empty defect. Original magnification $\times 40$, Toluidine blue stain. $\mathbf{O B}$, original bone; NB, new bone; $\mathbf{O}$, osteon; $\mathbf{B V}$, blood vessels.

\section{Group 2 (PRF Group)}

Most of the cavity was filled with newly formed bone. Although bone maturation was better than in the control group, there was no formation of secondary bone tissue. Osteocytes centered around the Volkmann and Haversian canals were seen. Despite the large number of cells, lamellar structures were not observed (Figure 3).

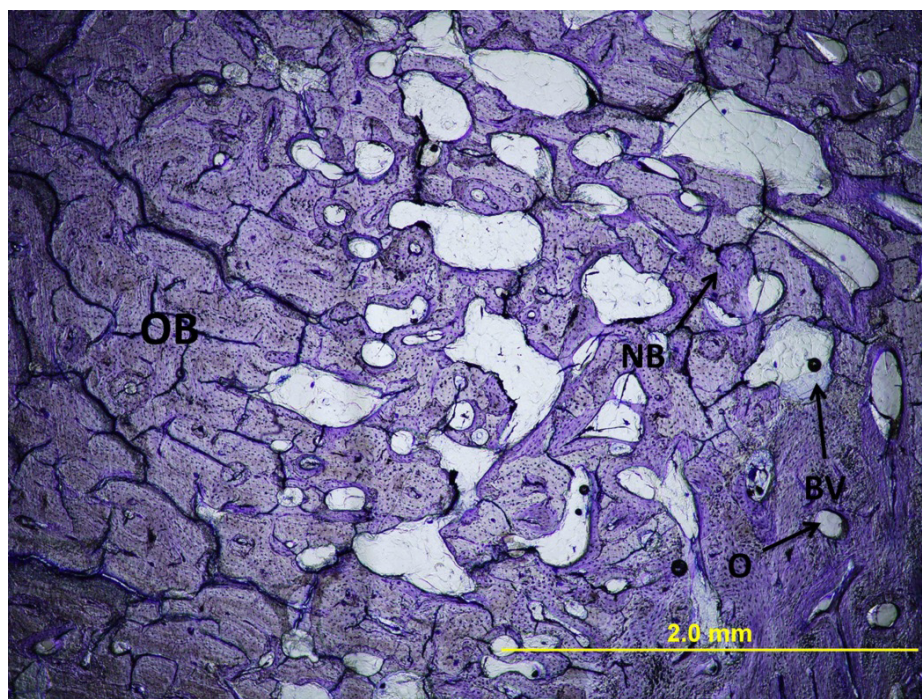

FIGURE 3 - Light micrograph of histology of PRF filled defect. Original magnification $\times 40$, Toluidine blue stain. $\mathbf{O B}$, original bone; $\mathbf{N B}$, new bone; $\mathbf{O}$, osteon; $\mathbf{B V}$, blood vessels.

\section{Group 3 ( $\beta$-TCP Group)}

The bone quality (smoothness of the osteon lamellae) was found to be better than in the first two groups. Remaining $\beta-$ TCP particles were identified and it was observed that these areas constituted the focus for the formation of new bone. Areas between the newly formed bones were intensely surrounded by erythrocytes and precursor cells of bone marrow (Figure 4).

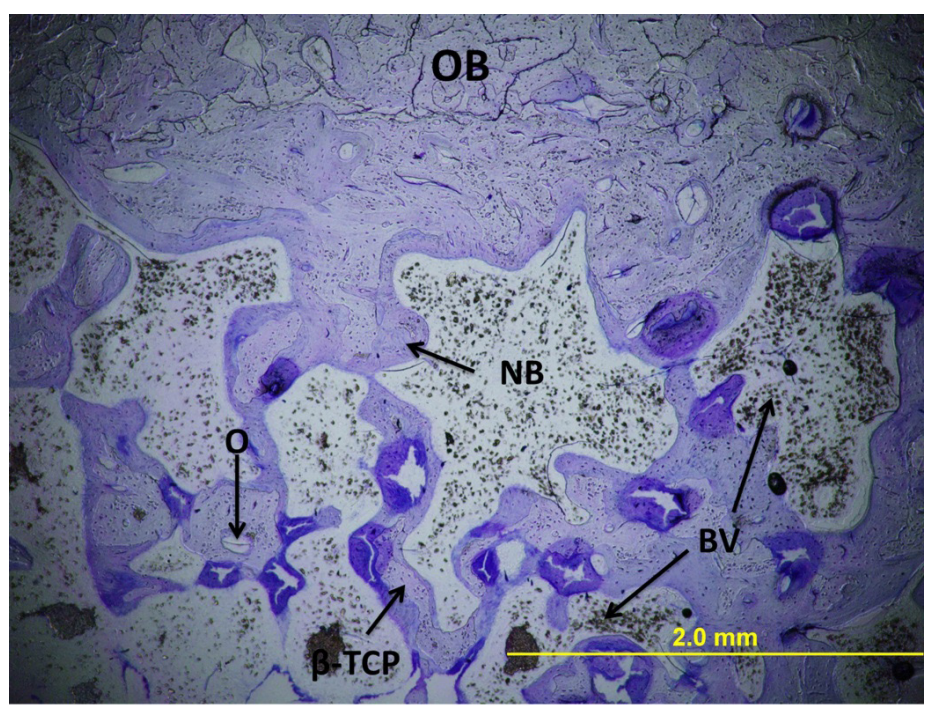

FIGURE 4 - Light micrograph of histology of $\beta$-TCP filled defect. Original magnification $x 40$, Toluidine blue stain. $\mathbf{O B}$, original bone; NB, new bone; $\mathbf{O}$, osteon; $\mathbf{B V}$, blood vessels; $\beta$-TCP, $\beta$-TCP granules.

\section{Group 4 ( $\beta$-TCP \pm PRF Group)}

A greater amount of new bone formation was seen in this group than in the other groups. Volkmann channels connecting normal osteon structures and Haversian channels were observed and $\beta-$ TCP graft material could not be found. Also, just as in the third group, a small number of areas were filled with erythrocytes and precursor cells of bone marrow were seen (Figure 5).

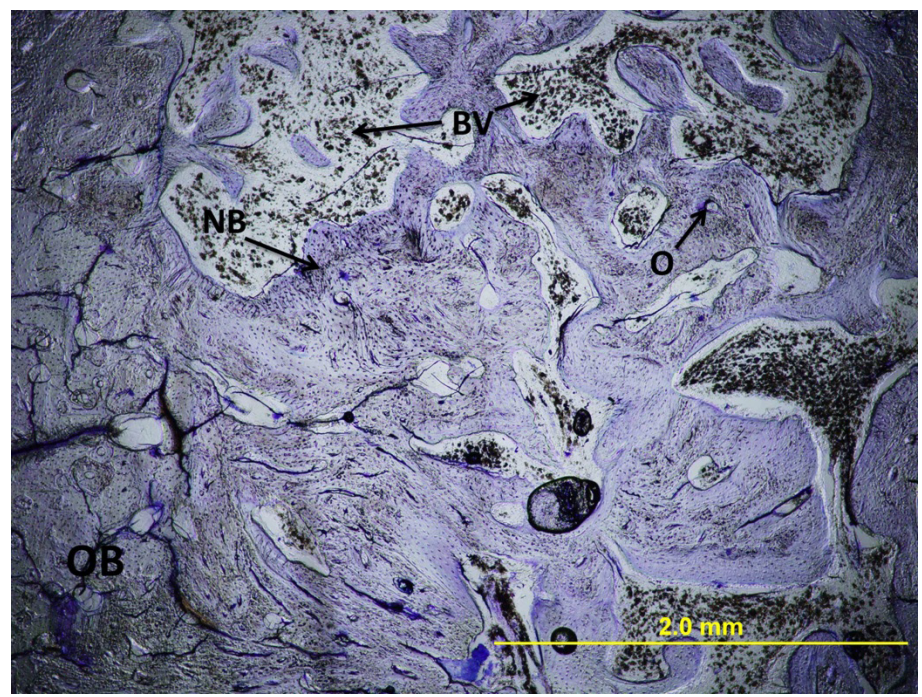

FIGURE 5 - Light micrograph of histology of PRF and $\beta$-TCP mixture filled defect. Original magnification $\mathrm{x} 40$, Toluidine blue stain. OB, original bone; NB, new bone; $\mathbf{O}$, osteon; $\mathbf{B V}$, blood vessels. 


\section{Stereometric analysis}

At the end of implantation period, new bone area was greater in all experimental groups than in the control group. The $\beta$-TCP/PRF group exhibited the biggest area of new bone. Statistical analysis showed that there was a significant difference between the experimental groups in the formation of new bone $(p=0.043)$ (Table 1). In order to determine which group caused this difference, post-hoc pairwise comparisons were made with the Bonferroni-corrected Mann-Whitney test and no statistically significant difference was found between the groups.

TABLE 1 - New formed bone area of groups $\left(\mu \mathrm{m}^{2}\right)$.

\begin{tabular}{lllllc}
\hline & Mim. & Max. & Mean & SD & p \\
\hline Control & 11.2 & 19.7 & 14.6 & 3.1 & $0.043^{*}$ \\
& & & & & \\
PRF & 13.5 & 27 & 18.2 & 5.1 & \\
$\beta-T C P$ & 18 & 25 & 21.1 & 2.8 & \\
PRF/ $\beta-$ & 16.2 & 36 & 22.1 & 7.4 & \\
TCP & & & & & \\
\hline
\end{tabular}

Mim: Minimum; Max: Maximum; SD: Standard deviation; * statistically significant

\section{Discussion}

The present study was designed to histologically and stereological investigate bone healing in standard defects filled with PRF and $\beta$-TCP alone or in combination in a pig model. Results showed that when a combination of PRF and $\beta$-TCP was used for bone defects, the area of the new bone formed was significantly greater than in the group treated with these materials alone. In addition, histological findings showed that the quantity and maturation of the new bone formation was different in each group. This suggests that the efficiency of $\beta$-TCP can be improved by the addition of PRF.

At the present time, different methods are being used for histological bone examination. The method we used in our study was first introduced and applied by Donath ${ }^{8}$. This method is used for examining hard tissues and biomaterials when it is impossible to prepare cross-sections by conventional methods. The advantages of this method are that it prevents damage to the bone matrix during decalcification and allows examination of both hard and soft tissues at the same time.

PRF is preferred to platelet rich plasma (PRP) because it does not contain any synthetic or anticoagulant materials, it is cheaper to prepare and the production time is shorter'. The advantage of the second generation thrombocyte concentration PRF to the first generation thrombocyte concentration PRP is biological activation. The effects of higher thrombin concentration of PRP are a fast polymerization time and uncontrolled fibrin matrix ${ }^{10}$. This situation is just the opposite for PRF. Permanent and long-lasting polymerization type provides a slow release of the contents (growth factors and cytokines), keeps them contained in the fibrin matrix for a long time and prevents them from undergoing proteolysis ${ }^{11}$.

Lee et $a{ }^{12}$ compared autogenous grafts with autogenous grafts plus PRF for sinus lifting operations. In the histomorphometric examination, the amount of the bone in autogenous graft /PRF combination group was more than in the group treated with autogenous bone grafts alone. In this situation, PRF activated the protein structure in the autogenous grafts and osteoblasts tended to adhere that were called into the environment area. In our study, when the PRF/ $\beta$-TCP combination group was compared with the others, more new bone formation, including osteoblasts and osteocytes in the connective tissue, was observed. It is thought that PRF accelerates the healing effect by keeping the particles of $\beta$-TCP together via its adhesive property and adapting them tightly to the walls of the cavity.

It is accepted that the suitable biomaterials used for bone regeneration should be resorbable and gradually replaced by the newly formed bone ${ }^{13}$. $\beta$-TCP has a low degradation rate and takes a longer period to be replaced by new bone tissue ${ }^{14}$. Previous histologic studies have shown that $\beta$-TCP particles are resorbed in 12-24 months and replaced with the newly generated bone in 36 months ${ }^{15}$. Wiltfang et al. ${ }^{16}$ compared the graft materials with PRP in pigs and they observed $\beta$-TCP particles remaining in the bone defects at $12^{\text {th }}$ week. At the end of the $12^{\text {th }}$ week of our study, $\beta$-TCP particles were observed histologically in the cavities that contained $\beta$-TCP alone, but no $\beta$-TCP particles were observed in the bone marrow when $\beta$-TCP and PRF has been used in combination. As a result, it can be stated that PRF increases the transformation of $\beta$-TCP particles into bone. Adding PRF to $\beta$-TCP was observed to significantly reduce the time required to promote graft consolidation, maturation, and improved trabecular bone density.

PRP and PRF can be applied in bone defects alone or in combination with other materials. Yazawa et al. ${ }^{17}$ studied PRP, $\beta$ TCP and fibrin adhesive in rabbits and they concluded that the use of PRP with synthetic graft materials is successful. Del Fabbro et $a l .{ }^{18}$ concluded from their study that the combined use of PRP with graft materials in bone defects contributes to wound healing. In the present study, $\beta$-TCP and PRF were used in combination and it was concluded that new bone formation was greater than in the 
other groups. In addition, PRF acts as a biologic adhesive to hold the particles together, making manipulation of the bone grafting material much easier.

Different studies have shown that there is complete biodegradation and new bone formation when $\beta$-TCP is used in bone defect 19 . Szabo et al. ${ }^{20}$ experimentally showed $\beta-$ TCP stimulated new bone formation even if resorption was slow. Similarly, in our study we saw that defects with $\beta$-TCP alone were completely filled with bone trabeculae coming from the periosteal surface, although maturation (remodeling) was not yet completed and the Haversian canal systems had not formed. Acceptable bone formation in the defect area, without complications such as infection or rejection, are positive effects of $\beta$-TCP on bone healing. In addition when defect areas filled with $\beta$-TCP were compared with the defects unfilled or filled with PRF alone, it was seen that new bone formation was more with the $\beta$-TCP.

\section{Conclusions}

The combination of platelet rich fibrin and beta tricalcium phosphate can accelerate bone healing more than when these materials are used alone. Combined use of PRF and $\beta$-TCP for bone healing is a potential treatment alternative for faster healing than using these biomaterials alone.

\section{References}

Kessler P, Thorwarth M, Bloch-Birkholz A, Nkenke E, Neukam FW. Harvesting of bone from the iliac crest: comparison of the anterior and posterior sites. Br J Oral Maxillofac Surg. 2005;43(1):51-6.

Moore WR, Graves SE, Bain GI. Synthetic bone graft substitutes. Aust N Z J Surg. 2001;71(6):354-61.

Schlegel K, Fichtner G, Schultze-Mosgau S, Wiltfang J. Histologic findings in sinus augmentation with autogenous bone chips versus a bovine bone substitute. Int J Oral Maxillofac Implants. 2003;18(1):53-8.

Koepp HE, Schorlemmer S, Kessler S, Brenner RE, Claes L, Gunther KP. Biocompatibility and osseointegration of beta-TCP: histomorphological and biomechanical studies in a weightbearing sheep model. J Biomed Mater Res B Appl Biomater. 2004;70(2):209-17.

Xin R, Leng Y, Chen J, Zhang Q. A comparative study of calcium phosphate formation on bioceramics in vitro and invivo. Biomaterials. 2005;26(33):6477-86.

Trombelli L, Heitz-Mayfield LJ, Needleman I, Moles D, Scabbia A. A systematic review of graft materials and biological agents for periodontal intraosseous defects. J Clin Periodontol. 2002;29(3):117-35.

Dohan DM, Choukroun J, Diss A, Dohan SL, Dohan AJ, Mouhyi J, Gogly B. Platelet-rich fibrin (PRF): a second-generation platelet concentrate. Part I: technological concepts and evolution. Oral Surg Oral Med Oral Pathol Oral Radiol Endod. 2006;101(3):e37-44.
Donath K, Breuner G. A method for the study of undecalcified bones and teeth with attached soft tissues: Sawing and grinding technique. J Oral Pathol. 1982;11(4):318-26.

Donath K. The diagnostic value of the new method for the study of undecalcified bones and teeth with attached soft tissue (SägeSchliff (sawing and grinding) technique). Pathol Res Pract. 1985;179(6):631-3.

Dohan DM, Rasmusson L, Albrektsson T. Classification of platelet concentrates from pure platelet-rich plasma (P-PRP) to leucocyte and platelet-rich fibrin (L-PRF). Trends Biotechnol. 2009;27(3):158-67.

Mosesson MW, Siebenlist KR, Mehn DA. The structure and biological features of fibrinogen and fibrin. Ann NY Acad Sci. 2001;936:11-30.

Lee HJ, Choi BH, Jung JH, Zhu SJ, Lee SH, Huh JY, You TM, Li J. Maxillary sinus floor augmentation using autogenous bone grafts and platelet-enriched fibrin glue with simultaneous implant placement. Oral Surg Oral Med Oral Pathol Oral Radiol Endod. 2007;103(3):329-33.

Giannoudis PV, Dinopoulos H, Tsiridis E. Bone substitutes: an update. Injury. 2005;36(3):20-7.

Walsh WR, Langdown AJ, Auld JW, Stephens P, Yu Y, Vizesi F, Bruce WJ, Pounder N. Effect of low intensity pulsed ultrasound on healing of an ulna defect filled with a bone graft substitute. J Biomed Mater Res B Appl Biomater. 2008;86(1):74-81.

Artzi Z, Weinreb M, Givol N, Rohrer MD, Nemcovsky CE, Prasad HS, Tal H. Biomaterial resorption rate and healing site morphology of inorganic bovine bone and beta-tricalcium phosphate in the canine: a 24-month longitudinal histologic study and morphometric analysis. Int J Oral Maxillofac Implants. 2004;19(3):357-68.

Wiltfang J, Kloss FR, Kessler P, Nkenke E, Schulze-Mosgau S, Zimmermann R, Schlegel KA. Effects of platelet-rich plasma on bone healing in combination with autogenous bone and bone substitutes in critical-size defects. Clin Oral Implants Res. 2004;15(2):187-93.

Yazawa M, Ogata H, Kimura A, Nakajima T, Mori T, Watanabe N. Basic studies on the bone formation ability by platelet rich plasma in rabbits. J. Craniofac Surg. 2004;15(3):439-46.

Del Fabbro M, Bortolin M, Taschieri S, Weinstein R. Is platelet concentrate advantageous for the surgical treatment of periodontal diseases? A systematic review and meta-analysis. J Periodontol. 2011;82(8):1100-11.

Ogose A, Kondo N, Umezu H, Hotta T, Kawashima H, Tokunaga K, Ito T, Kudo N, Hoshino M, Gu W, Endo N. Histological assessment in grafts of highly purified beta-tricalcium phosphate $\left(\right.$ OSferion $\left.^{\circledR}\right)$ in human bones. Biomaterials. 2006;27(8):1542-9.

Szabo G, Suba Z, Hrabak K, Barbaras J, Nemeth Z. Autogeneous bone versus $\beta$-tricalcium phosphate graft alone for bilateral sinus elevations. Preliminary results. Int J Oral Maxillofac Implants. 2001;16(5):681-92.

\section{Acknowledgement}

To Dr Hasan Ayberk Altug (Gulhane Military Medical Academy) for his kind advice in preparing this manuscript. 


\section{Correspondence:}

Aydin Ozkan

Head of Surgical Infirmary, Land Forces Practice Center

Sereflikochisar 06950, Ankara, Turkey

Phone: +905325234207

Fax: +903126878400

ydnozkan@yahoo.com

Received: Sept 12, 2013

Review: Nov 14, 2013

Accepted: Dec 12, 2013

Conflict of interest: none

Financial source: none

${ }^{1}$ Research performed at Experimental Animal Laboratory, Gulhane Military Medical Academy, Ankara, Turkey. 